\title{
On-Site Corrosion Behavior of Water-Treated Boiler Tube Steel
}

\author{
Junghwa Seo, Mihwa Choi ${ }^{1}$, Yinsheng He, Seok-Ran Yang ${ }^{1}$, Je-Hyun Lee, Keesam Shin* \\ School of Nano and Advanced Materials, Changwon National University, Changwon 51140, Korea \\ ${ }^{1}$ Green Growth Technology Laboratory, Korea Electric Power Research Institute, Daejeon 34056, Korea
}

*Correspondence to:

Shin $\mathrm{K}$,

Tel: +82-55-213-3696

Fax: +82-55-261-7017

E-mail: keesam@changwon.ac.kr

Received July 28, 2015

Revised August 2, 2015

Accepted August 2, 2015
The boiler tubes of X20CrMoV12.1 used in fossil-fired power plants were obtained and analyzed for the effect of water treatment on the steam corrosion-induced oxide scale in an effort to better understand the oxide formation mechanism, as well as pertinent method of maintenance and lifetime extension. The specimens were analyzed using various microscopy and microanalysis techniques, with focuses on the effect of water treatment on the characters of scale. X-ray diffraction analysis showed that the scales of specimens were composed of hematite $\left(\mathrm{Fe}_{2} \mathrm{O}_{3}\right)$, magnetite $\left(\mathrm{Fe}_{3} \mathrm{O}_{4}\right)$, and chromite $\left(\mathrm{FeCr}_{2} \mathrm{O}_{4}\right)$. Electron backscatter diffraction analysis showed that the oxides were present in the following order on the matrix: outer $\mathrm{Fe}_{2} \mathrm{O}_{3}$, intermediate $\mathrm{Fe}_{3} \mathrm{O}_{4}$, and inner $\mathrm{FeCr}_{2} \mathrm{O}_{4}$. After all volatile treatment or oxygenated treatment, a dense protective $\mathrm{Fe}_{2} \mathrm{O}_{3}$ layer was formed on the $\mathrm{Fe}_{3} \mathrm{O}_{4}$ layer of the specimen, retarding further progression of corrosion.

Key Words: All volatile treatment, Oxygenated treatment, Boiler tube, Corrosion behavior, Electron microscopy

\section{INTRODUCTION}

To produce fossil-fired power, steam is used to accelerate turbines and generate electrical energy. The conditions of the boilers, steam turbines, and heat exchangers are highly dependent on water treatment conditions. The type and density of the scale that forms in boiler tubes critically affect the lifetime and heat efficiency of the tubes, and thus, the entire system's ability to generate power.

Because constructing a new power plant is not only a matter of massive funding, but also of reaching a difficult sociopolitical consensus, it is highly necessary to ensure the efficiency and extension of power plant lifetime through successful maintenance (Burke \& Higginson, 2000; Chen et al., 2006; Ren et al., 2006; Zhang \& Shao, 2007; Chang et al., 2010). The operation conditions of power plants are getting more and more diverse and severe to the materials of major equipment such as boilers, steam turbines, reheaters $(\mathrm{R} / \mathrm{H})$, and super heaters $(\mathrm{S} / \mathrm{H})$ (Chen et al., 2006; Chang et al., 2010). Therefore, researchers have shown a great deal of interest in determining optimum water treatment technologies in various power plant operation conditions. Efficient water treatment would prevent boiler tubes from undesirable corroding, and reduce the necessary frequency of chemical cleaning for removal of scale in inner tubes-and thus, reducing the environmental contamination caused by power plants while extending their functional lifetime (Park \& Won, 1999). There already exist a variety of power plant water treatment methods, which can be separated into two categories: all volatile treatment (AVT), in which oxygen in the water is removed, and oxygenated treatment (OT), in which oxygen is added to the water (Cho et al., 2004). OT has been applied successfully for about a decade to power plants in Korea, and is known to suppress scale growth on water wall $(\mathrm{W} / \mathrm{W})$ tubes and lengthen interval between boiler tube chemical cleanings (Cho et al., 2004).

In this study, tubes that had been used for $\mathrm{S} / \mathrm{H}$ and $\mathrm{R} / \mathrm{H}$ under different service conditions for several thousands of hours in power plants were extracted and examined for corrosion behavior dependent on AVT or OT water treatment methods.

This work was supported by the National Research Foundation of Korea (NRF) grant funded by the Korea government (MSIP) (No. 2011-0030058).

@ This is an open-access article distributed under the terms of the Creative Commons Attribution Non-Commercial License (http://creativecommons.org/licenses/by-nc/4.0) which permits unrestricted noncommercial use, distribution, and reproduction in any medium, provided the original work is properly cited.

Copyrights (C) 2015 by Korean Society of Microscopy 
Table 1. Extracted specimen state and electron backscatter diffraction results on thickness of the oxide layers

\begin{tabular}{|c|c|c|c|c|c|c|c|c|c|c|}
\hline \multicolumn{2}{|c|}{ Sample } & \multirow{2}{*}{$\begin{array}{l}\text { Service } \\
\text { condition }\end{array}$} & \multirow{2}{*}{ Water treatment } & \multicolumn{3}{|c|}{ Service time (hr) } & \multicolumn{4}{|c|}{ Thickness $(\mu \mathrm{m})$} \\
\hline Type & Name & & & Total & AVT & OT & Total & $\mathrm{H}$ & M & $\mathrm{C}$ \\
\hline A & B4-SI99 & $\mathrm{S} / \mathrm{H}$ inlet & AVT & 50,051 & 50,051 & 0 & 85 & - & 55 & 30 \\
\hline B & B4-SI3 & S/H inlet & $\mathrm{AVT}+\mathrm{OT}$ & 79,409 & 1,032 & 78,377 & 102 & 11 & 36 & 55 \\
\hline$"$ & B4-SI7 & $"$ & $"$ & 111,866 & 2,160 & 109,706 & 118 & 13 & 55 & 50 \\
\hline $\mathrm{C}$ & B4-SO5 & S/H outlet & $\mathrm{AVT}+\mathrm{OT}$ & 95,954 & 1,752 & 94,202 & 121 & 25 & 33 & 63 \\
\hline$"$ & B4-SO7 & $"$ & $"$ & 111,866 & 2,160 & 109,706 & 213 & 38 & 65 & 110 \\
\hline$"$ & S6-SO1 & $"$ & $"$ & 29,266 & 480 & 28,786 & 137 & 24 & 32 & 81 \\
\hline$"$ & S6-SO3 & $"$ & $"$ & 45,306 & 1,056 & 44,250 & 138 & 22 & 40 & 76 \\
\hline$"$ & S6-SO5 & $"$ & $"$ & 65,936 & 1,608 & 64,328 & 173 & 29 & 41 & 103 \\
\hline$"$ & S6-SO7 & $"$ & $"$ & 77,604 & 2,204 & 75,400 & 201 & 22 & 76 & 103 \\
\hline $\mathrm{D}$ & B4-R5 & $\mathrm{R} / \mathrm{H}$ inlet & $\mathrm{AVT}+\mathrm{OT}$ & 95,954 & 1,752 & 94,202 & 84 & 8 & 25 & 51 \\
\hline$"$ & B4-R7 & $"$ & $"$ & 111,866 & 2,160 & 109,706 & 155 & 32 & 43 & 80 \\
\hline
\end{tabular}

$\mathrm{S} / \mathrm{H}$, super heaters; R/H, reheaters; AVT, all volatile treatment; OT, oxygenated treatment; $\mathrm{H}$, hematite; M, magnetite; $\mathrm{C}$, chromite.

\section{MATERIALS AND METHODS}

\section{Specimens}

In this study, the tempered martensite ferritic X20CrMoV12.1 steel with the composition of (wt\%) 0.17 0.23 C, 0.4 0.7 $\mathrm{Mn}, \sim 0.03 \mathrm{P}$ and S, 10 12.5 Cr, 0.8 1.25 Mo, 0.25 0.35 V, $0.3 \sim 0.8 \mathrm{Ni}$ and a balance of $\mathrm{Fe}$, which was used for heatexchanger tubes in a fossil-fired power plant, was extracted at $\sim 20,000$ hours intervals up to 111,866 hours as shown in Table 1 . The specimens were divided into four types $(\mathrm{A} \sim \mathrm{D})$ depending on their service condition (Table 2): the steam pressure in $\mathrm{S} / \mathrm{H}$ is about 6 times that of $\mathrm{R} / \mathrm{H}$, and the outlet temperature is about $50^{\circ} \mathrm{C}$ higher than the inlet. For type $\mathrm{A}$, only AVT water treatment was used. For types B, C, and D, water treatment was provided with AVT followed by OT. For AVT and OT water treatment, the oxygen concentrations were $<20 \mathrm{mg} / \mathrm{L}$ and 50 to $150 \mathrm{mg} / \mathrm{L}$, respectively.

\section{Microstructural Characterization}

Scale powders were collected from the steam side of each boiler tube sample and analyzed using X-ray diffractometer (XRD) with $\mathrm{CuK}_{\alpha}(\lambda=1.54056 \AA)$ in the $2 \theta$ of $10^{\circ}$ to $120^{\circ}$. Optical microscope (OM), scanning electron microscope (SEM), electron backscatter diffraction (EBSD), and transmission electron microscope (TEM) analyses were employed to characterize the thickness, structure, and phase of each scale layer. EBSD was used to analyze the phase and structure of the scale, whose specimens were prepared by mechanical polishing followed by 4 hours colloidal silica finishing. The specimens were then analyzed using SEM (FESEM, MIRA II LMH; TESCAN, Czech) and energy dispersive spectrometer (EDS). The scale layers that could not be analyzed by EBSD were collected and analyzed with TEM/
Table 2. Service condition of extracted specimens used in this study

\begin{tabular}{lcc}
\hline Service condition $/$ part & $\mathrm{S} / \mathrm{H}$ & $\mathrm{R} / \mathrm{H}$ \\
\hline Pressure $\left(\mathrm{kg} / \mathrm{cm}^{2}\right)$ & & \\
Inlet & 258.4 & 41.5 \\
Outlet & 255.0 & 40.6 \\
Temperature $\left({ }^{\circ} \mathrm{C}\right)$ & & \\
Inlet & 493 & 455 \\
Outlet & 541 & 541 \\
\hline
\end{tabular}

$\mathrm{S} / \mathrm{H}$, super heaters; $\mathrm{R} / \mathrm{H}$, reheaters.

EDS (JEM-2100F; JEOL, Japan), using specimens prepared by placing a droplet of crumbled and supersonically dispersed scale powders into ethyl alcohol on a carbon film grid.

\section{RESULTS AND DISCUSSION}

\section{OM and SEM/EDS Analysis}

Though OM analysis is favorable for observing the morphology and characteristics of scale (results not shown); however, phase and composition must be analyzed using other methods. Fig. 1 shows typical SEM and EDS mappings of one of the specimens (type B, B4-SO5). SEM (Fig. 1A) and EDS (Fig. 1B-D) analyses revealed that two oxide layers, in order of Fe-rich oxide layer and Cr-rich oxide layer on the matrix (far right). Voids are aligned along the phase boundary of the scale samples.

\section{XRD/EBSD Phase Analysis}

XRD identification of phases in the oxide scale samples was conducted prior to EBSD analysis (Fig. 2). Scales were hematite and magnetite (the chromite phase is not inde- 

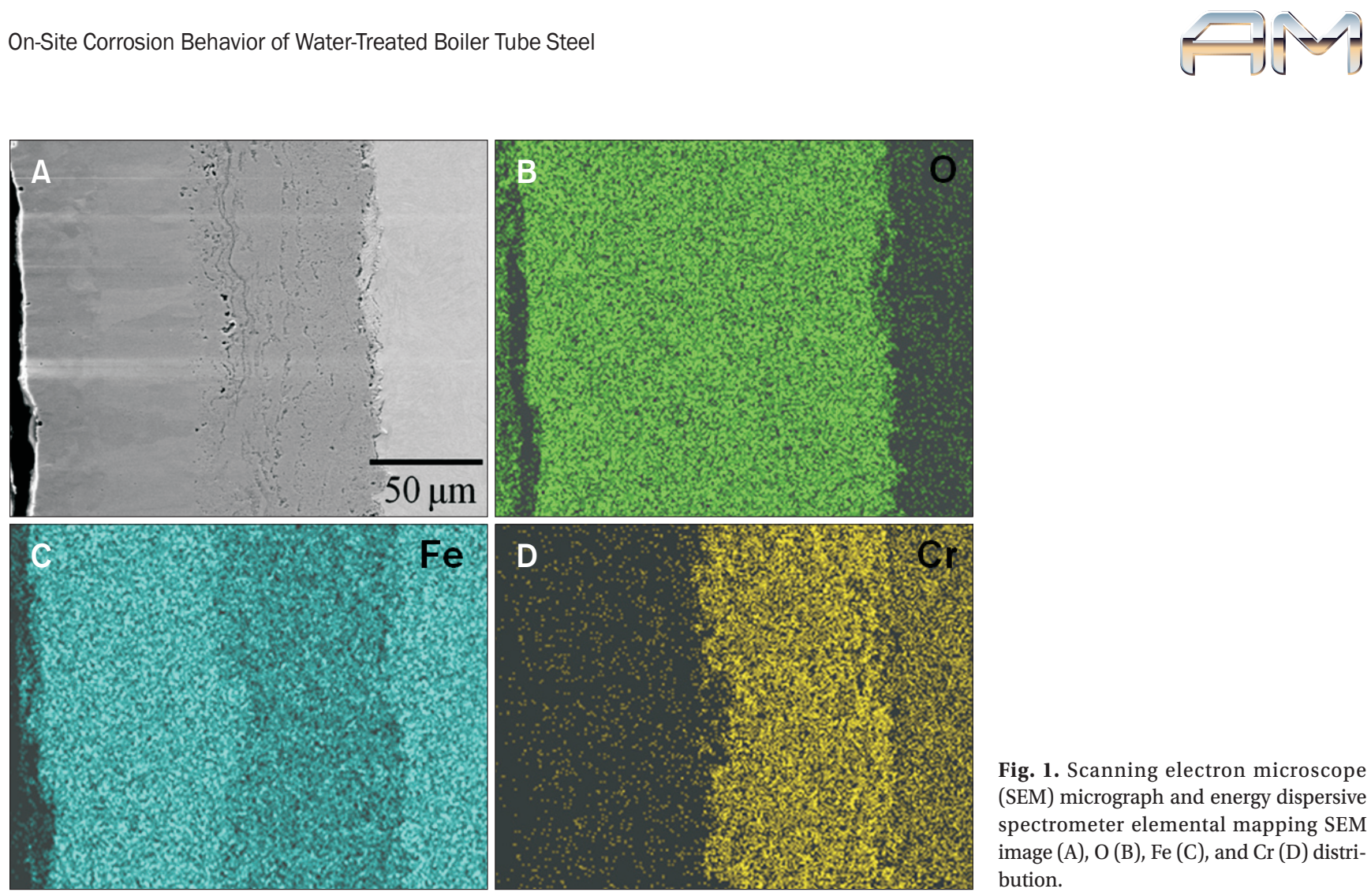

Fig. 1. Scanning electron microscope (SEM) micrograph and energy dispersive spectrometer elemental mapping SEM image (A), O (B), Fe (C), and Cr (D) distribution.

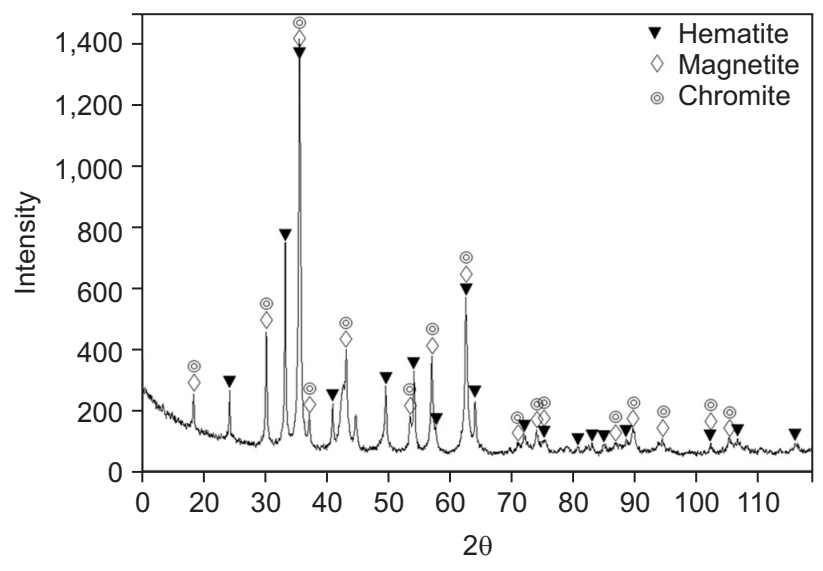

Fig. 2. Typical X-ray diffractometer spectrum of scale (B4-SO7).

pendently identified by XRD/EBSD). The reason XRD could not yield peaks from $\mathrm{Cr}$ oxide, even though the thickness was over $50 \mu \mathrm{m}$, is that the peaks overlapped those of the hematite and magnetite due to similarities in the lattice parameters (especially magnetite). Subsequent EBSD analysis was therefore necessary to identify the phase unresolved by XRD, and the relative distributions of the scale phases.

The phase distribution of the oxide layers shown in Fig. 3; those not well-resolved by SEM analysis (Fig. 1A) were clearly resolved by EBSD analysis. Fig. $3 \mathrm{~A}$ and $\mathrm{B}$ are EBSD phase mappings of type $A, C$, and $D$ specimens, in which inner chromite layers, middle magnetite layers, and outer hematite layers were investigated. Hematite layers were observed only in OT-treated specimens (the matrix of $\mathrm{S} / \mathrm{H}$ and $\mathrm{R} / \mathrm{H}$ specimens was $\alpha$-ferrite). Fig. 3C shows the EBSD results of OT-treated $\mathrm{R} / \mathrm{H}$ scale. The phase and oxide layer order were the same for all samples regardless of treatment, apart from the fact that the grain size of the hematite and magnetite were larger in S/ $\mathrm{H}$ which can be attributed the higher operation temperature of $\mathrm{S} / \mathrm{H}$.

\section{TEM Chromite Phase Identification}

The dark Cr-rich layer unresolved by SEM-EDS (Fig. 1) or EBSD analyses (Fig. 3) was further characterized using TEM. Fig. 4A shows a TEM micrograph of the crumbled scale sample on a carbon grid; the TEM/EDS results (Fig. 4D) show that it was Cr-rich, similar to the SEM/EDS results of the inner Cr-rich layers. Diffraction (selected area diffraction pattern, SADP) (Fig. 4B) and high-resolution TEM (HRTEM) (Fig. 4C) image analyses revealed that the Cr-rich layer had cubic structure with $\mathrm{a}=8.4 \AA$, and grain size of 10 to $15 \mathrm{~nm}$, which characterize $\mathrm{FeCr}_{2} \mathrm{O}_{4}$. Thus, it is understandable that XRD and EBSD failed to resolve the $\mathrm{FeCr}_{2} \mathrm{O}_{4}$ phase, due to nano-level grain size. The results also show that a dense, Crrich oxide layer just after the matrix; according to previous research, this layer protected the matrix from corrosion (Kim et al., 2004; Dooley et al., 2005; Song et al., 2008; He et al., 2011). 

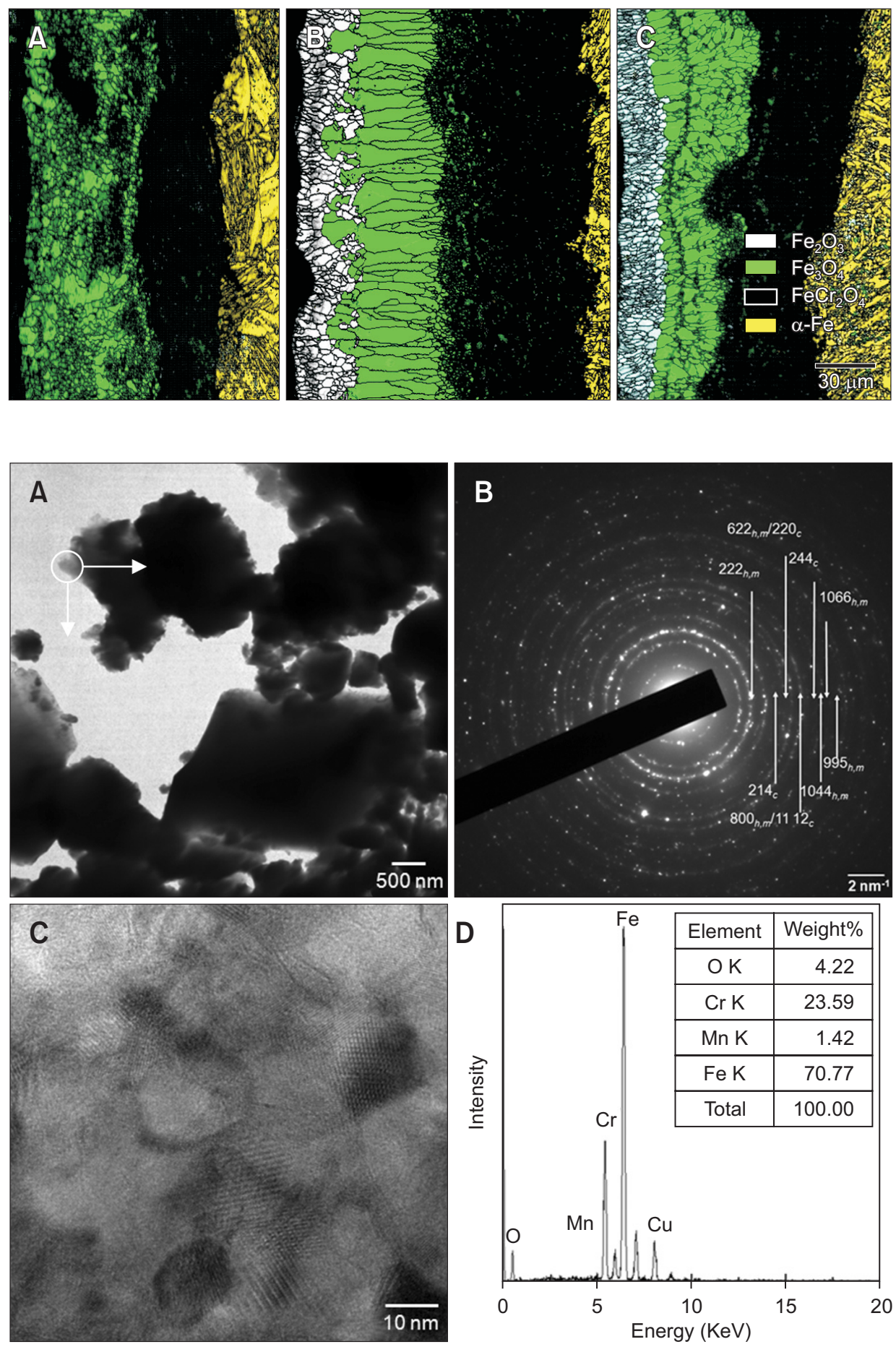

Fig. 4. Transmission electron microscope (TEM) analysis results of the chromite layer $\left(\mathrm{FeCr}_{2} \mathrm{O}_{4}\right.$ layer): low magnification powder (A), selected area diffraction pattern (B), high-resolution TEM image (C), and EDS spectrum (D) of the area marked in Fig. 4A.
Fig. 3. Electron backscatter diffraction images showing phase distribution of the scale in type A (A; AVT treated, 50, 051 hours $\mathrm{S} / \mathrm{H}$ inlet serviced), type $\mathrm{C}$ (B; AVT/OT treated, 95, 954 hours S/ $\mathrm{H}$ outlet serviced), and type D (C; AVT/ OT treated, 95, 954 hours $\mathrm{R} / \mathrm{H}$ inlet serviced) X20CrMo12.1 boiler tube steel. AVT, all volatile treatment; $\mathrm{S} / \mathrm{H}$, super heaters; OT, oxygenated treatment; $\mathrm{R} / \mathrm{H}$, reheaters.

\section{Comparison of Scale}

The phase and thickness of scale (including each layer) of the specimens were investigated using EBSD phase mapping (Fig. 5). The thickness of the total scale (B, C, D-total) increased as service time increased.

In the AVT-treated specimen (type A), there was no hematite observed due conceivably to low oxygen partial pressure in 

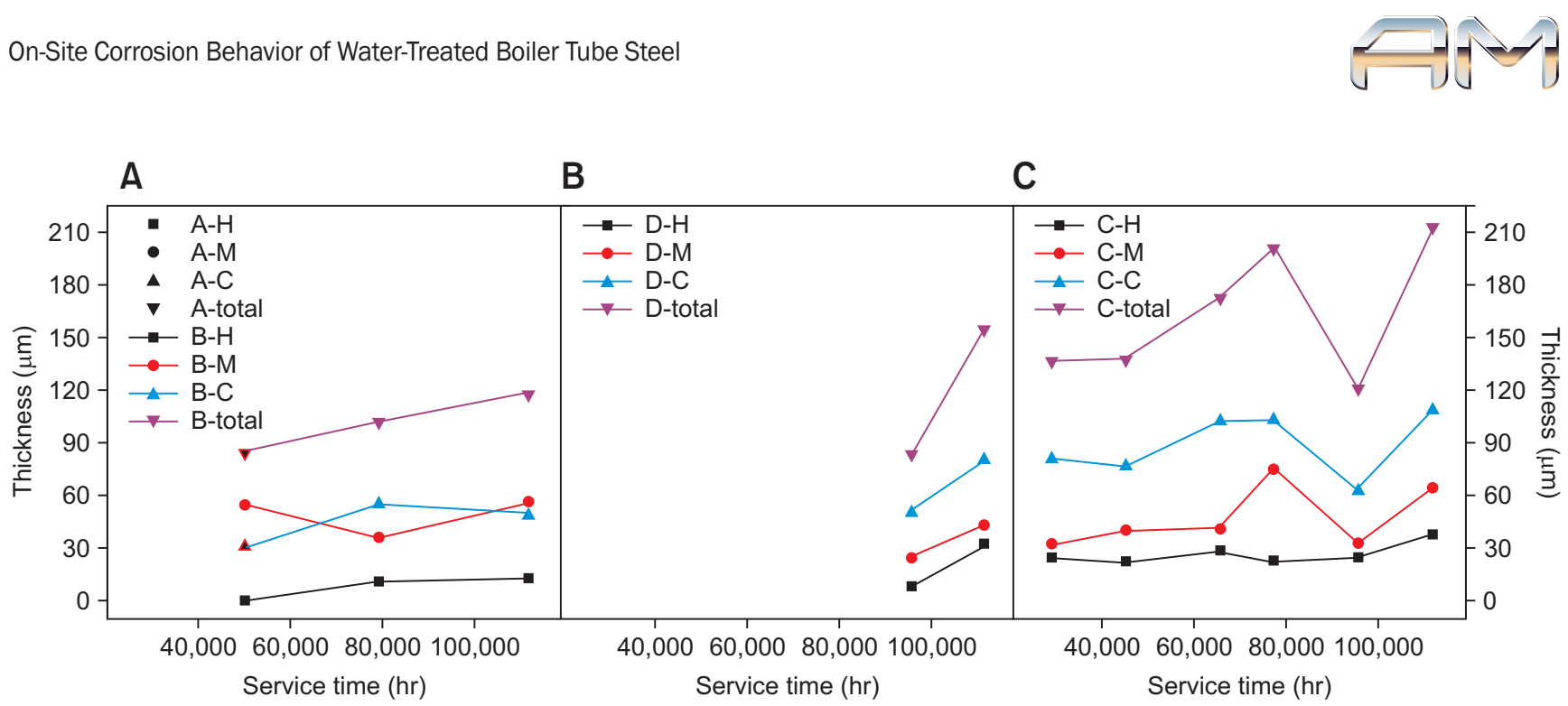

Fig. 5. Electron backscatter diffraction results on the scale thickness as a function of service time of the investigated specimens: type A and B specimens

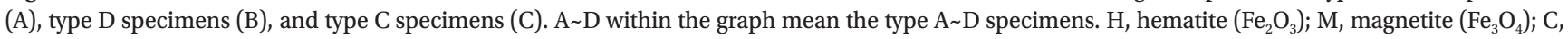
chromite $\left(\mathrm{FeCr}_{2} \mathrm{O}_{4}\right)$.

side, indicating that scale growth increased as temperature increased. A likely reason for this is that the concentration of dissolved oxygen increased as temperature increased. Although the pressure in the type D specimen was about 6 times higher than that of type B (Fig. 5A and B), the oxide growth rate in type $\mathrm{D}$ was higher than in type $\mathrm{B}$, suggesting that the growth rate of oxide scale is more dependent on temperature than pressure, contrary to prior research. Hematite grew more quickly than magnetite in all specimens, most likely due to the dense characteristics of hematite and passivity of magnetite (Fig. 3).

As shown in Table 1, Fig. 3, and Fig. 5, the thickness of chromite layers increased as service time increased, regardless of which water treatment method was applied. The thickness of hematite layers was relatively stable, however, regardless of service time. A relatively thin hematite layer was observed on the surface of the magnetite layer after water treatment was changed from AVT to OT, though the scale was expected to be mostly hematite due to the lengthy duration of OT. During high-temperature service, oxide layer formation on the surface of the metal matrix is completed by the outward diffusion of Fe ions and inward diffusion of oxygen ions ( $\mathrm{He}$ et al., 2011). The formation of a dense chromite layer (due to nano-sized chromite) prevents the outward diffusion of $\mathrm{Fe}$ through the porous magnetite (Fig. 3A), which form passages for the inward diffusion of oxygen. The formation of an outermost fine hematite layer further prevents the inward diffusion of oxygen ions, enhancing corrosion resistance. The inner chromite layer grows as service time increases, while the outer hematite layer remains relatively stable.

\section{SUMMARY}

The effects of water treatment (AVT and OT) on the inner scale of boiler tubes used in fossil-fired power plants for 10,000 to 110,000 hours were analyzed in this study to characterize scale formations and collect data for the optimized operation and lifetime extension. The boiler tubes of $\mathrm{S} / \mathrm{H}$ and $\mathrm{R} / \mathrm{H}$ under different service conditions were extracted and analyzed using XRD, OM, SEM/EDS/EBSD, and TEM/EDS. The formation and growth of the scale was dependent on the water treatment method. The most notable findings of this study can be summarized as follows:

(1) When AVT was applied, chromite and porous magnetite were formed on top of the matrix. When the water treatment was changed to OT from AVT, chromite and dense magnetite formed on the matrix; additionally, a dense hematite layer was formed on top of the two layers after the treatment was changed to OT.

(2) The growth rates of the scale were largely dependent on the operation temperature, with which increase the grain size of hematite and magnetite. The growth rate of the oxide layer was increasing in the order of 1) hematite, 2) magnetite, and 3) chromite.

(3) In AVT-treated specimens, the formation of nano-sized chromite in the interface of the chromite layer/matrix prevents corrosion. When specimens were treated with OT after AVT, the formation of dense hematite layers on the outer oxide layer prevented the tubes from further corroding.

\section{CONFLICT OF INTEREST}

No potential conflict of interest relevant to this article was reported. 


\section{REFERENCES}

Burke D P and Higginson R L (2000) Characterisation of multicomponent scales by electron back scattered diffraction (EBSD). Scripta Mater. 42, 277-281.

Chang J C, Heo N H, and Lee C H (2010) Intergranular cracking susceptibility of $2.25 \mathrm{Cr} 1.3 \mathrm{~W}$ and $9 \mathrm{Cr} 1 \mathrm{MoVNb}$ weld metals at elevated temperatures. Met. Mater. Int. 16, 981-985.

Chen Y, Sridharan K, and Allen T (2006) Corrosion behavior of ferriticmartensitic steel T91 in supercritical water. Corros. Sci. 48, 28432854.

Cho S H, Lim J H, Chung J H, Hur J M, Seo C S, and Park S W (2004) Hot corrosion behavior of austenite alloys in lithium molten salt under oxidation atmosphere. J. Korean Ind. Eng. Chem. 15, 913-919.

Dooley R B, Shields K, Aschoff A, Ball M, Bursik A, Gruszkiewicz M, Marais S, and Swainsbury D (2005) EPRI Final Report: Cycle Chemistry Guidelines for Fossil Plants: Oxygenated Treatment (Electric Power Research Institute, Palo Alto).

He Y S, Chang J C, Dong J L, and Shin K S (2011) Microstructural evolution of X20CrMoV12.1 steel upon long-term on-site exposure in power plants. Adv. Sci. Lett. 4, 1416-1423.

Kim H S, Yoon J H, Han J H, Mitton B D, Latanision R M, and Kim Y S (2004) Influence of chromizing treatment on the corrosion behavior of AISI 316 stainless steel in supercritical water oxidation. Met. Mater. Int. 10, 83-88.

Park K G and Won D Y (1999) A study on the effect of dissolved oxygen on FAC in supercritical boiler. Corro. Sci. Technol. 28, 152-160.

Ren X, Sridharan K, and Allen T R (2006) Corrosion of ferritic-martensitic steel HT9 in supercritical water. J. Nucl. Mater. 358, 227-234.

Song K O, Cho T Y, Yoon J H, Lee C G, Shin K S, Lee S H, Urm K W, Lee J W, and Kim I S (2008) Steam oxidation and surface hardness of power plant valve materials under the ultra-super critical steam condition. Met. Mater. Int. 14, 721-727.

Zhang M Y and Shao G J (2007) Characterization and properties of oxide scales on hot-rolled strips. Mater. Sci. Eng. A 452-453, 189-193. 